\title{
The flgK motility operon of Borrelia burgdorferi is initiated by a $\sigma^{70}$-like promoter
}

\author{
Yigong Ge, ${ }^{1}$ lain G. Old, ${ }^{2}$ Isabelle Saint Girons ${ }^{2}$ and Nyles W. Charon'
}

1 Department of Microbiology, West Virginia University, Health Sciences Center, Box 9177, Morgantown, West Virginia 26506-9177, USA

2 Unité de Bactériologie Moléculaire et Médicale, Institut Pasteur, 75724 Paris, Cédex 15, France
Author for correspondence: Nyles W. Charon. Tel: +1 304293 4170. Fax: + 13042937823. e-mail: charon@wvnvms.wvnet.edu

A cluster of flagellar genes of Borrelia burgdorferi was identified and sequenced. This cluster comprises an operon, designated the flgK operon, which is initiated by a $\sigma^{70}$-like promoter. The figK operon consists of flbF (function unknown), flgK (encoding HAP1), flgL (encoding HAP3) and orfX (function unknown), and maps at $185 \mathrm{~kb}$ on the chromosome. In other bacteria, the hook-associated proteins HAP1 and HAP3 connect the flagellar filament to the hook and are required for the last stage of flagellar assembly. Reverse transcriptase-PCR analysis indicated that $f / b F$ through to orf $X$ are transcribed as a single mRNA, and primer extension analysis revealed that transcription of the flgK operon is initiated by a $\sigma^{70}$-like promoter upstream of flbF. Subcloning the flgK promoter element into a promoter probe cat vector revealed that the flgK promoter element had strong activity in both Escherichia coli and Salmonella typhimurium. In addition, when this construct was transformed into a fliA mutant of $S$. typhimurium which lacked a functional flagellarspecific $\sigma^{28}$ factor, the figK promoter was still functional. Based on these results, the promoter element of the flagellin gene (fla, hereafter referred to as flaB) was re-examined. flaB encodes the flagellar filament protein, and a

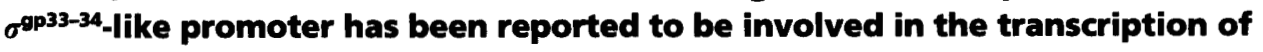
this gene. A transcriptional start point was found 1 bp downstream of the reported start site. The sequence around -10 and -35 are consistent with the presence of a $\sigma^{70}$-like promoter in addition to the putative $\sigma^{\text {op } 33-34-\text { like promoter }}$ for flaB. In contrast to the flgK promoter element, no activity was detected after subcloning a flaB promoter element into the promoter probe cat vector. Because a $\sigma^{70}$-like promoter rather than a unique flagellar sigma factor is involved in the later stage of flagellar assembly, the regulation of $B$. burgdorferi flagellar genes is evidently different from that of other bacteria.

Keywords: Borrelia burgdorferi, motility, flagella, hook-associated protein, sigma factor

\section{INTRODUCTION}

The flagellum is a complicated organelle essential for the motility of many species of bacteria. A typical flagellum consists of a terminal cap protein, filament, hookassociated proteins and a hook-basal body complex. Located at the cell membrane and within the cytoplasm

Abbreviations: CAT, chloramphenicol acetyltransferase; HAP, hookassociated protein; PF, periplasmic flagellum; RT-PCR, reverse transcriptase-PCR; SRPCW, semi-random PCR chromosome walking.

The GenBank accession numbers for the sequences of the flgK operon and of the upstream region of $f l a B$ reported in this paper are U62901 and U66699, respectively. are the components required for flagellar synthesis, chemotaxis and motility. Over forty motility and chemotaxis genes have been identified in Escherichia coli and Salmonella typhimurium; these genes are arranged in large clusters on the chromosome. In E. coli these clusters include four motility regions (region I, II, IIIa and IIIb), which consist of 15 operons (Aizawa, 1996; Macnab, 1996).

In several species of bacteria, expression of flagellar genes is tightly controlled in a transcriptional hierarchy (Fredrick et al., 1995; Helmann, 1991; Kutsukake \& Ide, 1995; Macnab, 1996; Marquez-Magana \& Chamberlin, 1994; Mohr et al., 1996; Wu et al., 1995). 
Specifically, the expression of early-stage genes is a prerequisite for activation of the later-stage genes during flagellar synthesis. For example, in E. coli and $S$. typhimurium, expression of the class 1 master genes is essential for activation of the class 2 operons which encode proteins required for the early assembly of the flagellum (Helmann, 1991). The flagellar-specific $\sigma^{28}$ factor, which is encoded by a class 2 gene, augments transcription of the class 3 operons which encode flagellin, hook-associated proteins (HAPs), proteins involved in chemotaxis and negative regulatory proteins (Aizawa, 1996; Helmann, 1991; Macnab, 1996). A similar regulatory cascade is observed in Caulobacter crescentus and Bacillus subtilis, but in C. crescentus flagellar synthesis is tightly coupled to cell division (Mohr et al., 1996; Quon et al., 1996; Zhuang \& Shapiro, 1995). Like other bacterial sigma factors, flagellar-specific sigma factors recognize a specific consensus sequence (Helmann, 1991; Macnab, 1996). The well conserved $\sigma^{28}$-like promoter elements are involved in the transcription of most class 2 and class 3 operons in enteric bacteria and B. subtilis (Fredrick et al., 1995; Fredrick \& Helmann, 1994; Macnab, 1996; MarquezMagana \& Chamberlin, 1994; Mirel et al., 1992). In C. crescentus, a similar $\sigma^{54}$ promoter is required for class 3 and 4 operons (Anderson et al., 1995; Ramakrishnan et al., 1994; Wu et al., 1995).

Borrelia burgdorferi is a motile, pathogenic spirochaete which causes Lyme disease. The outermost layer of the cell is a membrane sheath, and within this sheath is the cell cylinder and periplasmic flagella (PFs). The PFs are attached near each end of the cell cylinder and are morphologically similar to the flagella of other bacteria (Hovind Hougen, 1984). Genetic evidence indicates that the PFs are involved in motility and rotate in a manner similar to the flagella of rod-shaped bacteria (Goldstein et al., 1994; Sadziene et al., 1991). Several lines of evidence suggest that motility is important for this organism to infect the mammalian host. First, after being deposited in the skin as a consequence of a tick bite, the spirochaetes must traverse the intercellular matrix and eventually enter the bloodstream (Kimsey \& Spielman, 1990). In fact, B. burgdorferi and other spirochaetes have the unique ability to efficiently swim in gel-like media such as collagen fibres and hyaluronic acid (Canale-Parola, 1978; Goldstein et al., 1994; Kimsey \& Spielman, 1990). Second, genetic experiments implicate motility as an important virulence factor. Specifically, Sadziene et al. (1991) found that a spontaneous nonmotile mutant ( $\mathrm{HB19Fla}{ }^{-}$) is less invasive than wild-type $B$. burgdorfer $i$ in cell penetration assays. Finally, because more than 38 genes, or approximately $3.5 \%$ of its genome, are dedicated to motility and chemotaxis (our unpublished results; Gassmann et al., 1991; Ge et al., 1996), motility may be presumed vital for B. burgdorferi to survive in nature (Armitage, 1992).

The mechanism underlying motility of B. burgdorferi is poorly understood. Most of the information obtained has been based primarily on morphological observations of swimming cells and an analysis of PF structure
(Goldstein et al., 1994, 1996; Hovind Hougen, 1984). The absence of a gene exchange system in B. burgdorferi has severely impaired the study of motility at a molecular level. To elucidate the role of motility in the development of Lyme disease, we initiated a genetic analysis of the flagellar system of B. burgdorferi (Ge et al., 1996).

In this report we describe a flagellar operon containing at least four genes. Within this operon, three putative flagellum-related genes were sequenced and its promoter region analysed in detail. In contrast to the flagellar genes of other bacteria, a $\sigma^{70}$-like promoter was found to be involved in the transcription of this operon. In addition, because the promoter of the flagellin operon ( $f l a$, hereafter referred to as $f l a B$ ) of $B$. burgdorferi has been reported to utilize a $\sigma^{\mathrm{gp33} 34}$ promoter sequence (Noppa et al., 1995), we re-examined this promoter and also found it to be $\sigma^{70}$-like. This is the first report to our knowledge of $\sigma^{70}$-like promoters being involved in the transcription of a flagellar hook-basal body operon in bacteria.

\section{METHODS}

Bacterial strains, plasmids and growth conditions. French isolate of $B$. burgdorferi sensu stricto strain 212, Northern American isolate of $B$. burgdorferi strain HB19 and a spontaneous PF mutant obtained from strain HB19 (HB19Fla ${ }^{-}$) were used in this study (Sadziene et al., 1991). B. burgdorferi were grown in BSK-II medium (Barbour, 1984). E. coli DH5 $\alpha$ (Bethesda Research Laboratory) and HB101 (Promega) were used for propagation of plasmids or for the chloramphenicol acetyltransferase (CAT) assay. E. coli and $S$. typhimurium strains were grown in LB medium or 2YT medium (Sambrook et al., 1989). Bacteria carrying recombinant plasmids were maintained in the presence of antibiotics at the relevant concentrations (ampicillin, $50 \mu \mathrm{g} \mathrm{ml}^{-1}$ and/or chloramphenicol, $25 \mu \mathrm{g} \mathrm{ml}^{-1}$ ). The plasmids used in this study are listed in Table 1.

DNA analysis. Restriction enzymes and other enzymes were used as directed by the suppliers (New England Biolabs, Life Technology and Promega). Plasmids were isolated using Qiagen Mini or Midi plasmid isolation kits. B. burgdorferi genomic DNA was isolated as described by Ausubel et al. (1995). Inserts were sequenced on both strands by the Sanger method (Sanger et al., 1977). The sequencing strategy was subcloning and internal primer walking. DNA sequence data were analysed using DNASTAR and DNASIS, along with on-line BLAST.

Cloning and mapping the genes upstream of flgK. By random sequencing of a previously constructed partial EcoRI bank from B. burgdorferi strain 212, we isolated the gidA, gidB and thdF genes of strain 212 which mapped at $185 \mathrm{~kb}$ on the chromosome and are transcribed toward the 0 telomer (Saint Girons et al., 1994). Extended sequencing of the region adjacent to $t h d F$ revealed an ORF with identity to $f \lg K$ of B. subtilis, and that this ORF is transcribed in the opposite orientation to that of $t h d F$ (I. Saint Girons \& I. G. Old, unpublished).

Semi-random PCR chromosome walking (SRPCW). To sequence part of $f g K$ and the downstream genes, we used the new method of SRPCW (unpublished). This method is a modification of that described by Parker et al. (1991). A specific primer (5'-CCCAATGAATTTTTAATCC-3') gen- 
Table 1. Plasmids used in this study

\begin{tabular}{|c|c|c|}
\hline Plasmid & Description & Reference or source \\
\hline $\mathrm{pNoTA} / \mathrm{T} 7$ & Amp ${ }^{r}$ PCR cloning vehicle & $5^{\prime} \rightarrow 3^{\prime}$, Inc. \\
\hline pGEM-T & Amp ${ }^{r}$ PCR cloning vehicle & Promega \\
\hline pCR II & $A m p^{r}$ and $K_{a n}{ }^{r}$ PCR cloning vehicle & Invitrogen \\
\hline pKK232-8 & Amp $^{r}$ promoter probe vehicle with promoterless cat gene & Brosius (1984) \\
\hline pER187 & $A m p^{r}$ derived from pUC19 with a mobile cat gene from $S$. aureus & $\begin{array}{l}\text { E. Rosey, Pfizer, } \\
\text { Groton, CT, USA }\end{array}$ \\
\hline pflgKL & $3.0 \mathrm{~kb}$ PCR fragment containing $f l g K$ and $f g L$ genes cloned into pNoTA/T7 vector & This study \\
\hline pflaBp & $1.0 \mathrm{~kb}$ PCR fragment containing the sequence upstream of $f l a B$ gene cloned into pGEM-T & This study \\
\hline ppflgK & pKK232-8 with $230 \mathrm{bp}$ insert from flgK promoter element & This study \\
\hline ppflaB & pKK232-8 with $130 \mathrm{bp}$ insert from $\mathrm{flaB}$ promoter element & This study \\
\hline
\end{tabular}

erated from the $5^{\prime}$-end of $f l g K$ was paired with a random primer $\left(5^{\prime}\right.$-GCGTGAAAGA-3') for the amplification of the 3 '-end of $f l g K$ under low-stringency PCR conditions. The nucleotide composition of the random primers is slightly higher in $\mathrm{G}+\mathrm{C}$ content than that of the $B$. burgdorferi genome, which is $27 \mathrm{~mol} \% \mathrm{G}+\mathrm{C}$ (Johnson et al., 1984). For amplification, the PCR reaction was carried out with $200 \mathrm{ng}$ of B. burgdorferi DNA and $100 \mathrm{pmol}$ each of the specific primer and the random primer using PrimeZyme (Biometra). Amplification was carried out at $94^{\circ} \mathrm{C}$ for $1 \mathrm{~min}, 43^{\circ} \mathrm{C}$ for $1 \mathrm{~min}$ and $72{ }^{\circ} \mathrm{C}$ for $5 \mathrm{~min}$ for 35 cycles in $5 \mathrm{mM} \mathrm{MgCl} \mathrm{M}_{2}$. The PCR products were analysed in $1 \%$ agarose gels, purified using a Qiagen PCR purification kit and cloned into pGEM-T. After selecting five clones for DNA sequencing, one positive clone (pflgKL) with a $3.0 \mathrm{~kb}$ insert was found to contain the remaining portion of the $f l g K$ gene and an intact $f l g L$ gene (Table 1). The sequence of the fragment was further verified by repeating the PCR amplification under high-stringency conditions using $P f u$ DNA polymerase (Stratagene) which has higher fidelity, together with specific primers generated from the new sequence data from the 3 -end of $\mathrm{flgL}$. The amplified products were cloned into the pNoTA/T7 vector. For the high-stringency reaction, the annealing temperature was raised to $52{ }^{\circ} \mathrm{C}$ and the concentration of $\mathrm{MgCl}_{2}$ was decreased to $1.5 \mathrm{mM}$. The same strategy was utilized to amplify a segment upstream of the $f l a B$ operon. By using a specific primer, 5'-TGAAGCATTAATAGCTGATG-3', and a random primer, $\left(5^{\prime}\right.$-CCTTTAAGGAA-3'), a $1.0 \mathrm{~kb}$ PCR fragment was amplified and cloned into pGEM-T, resulting in the plasmid pflaBp.

Isolation of total RNA, primer extension and reverse transcriptase-PCR (RT-PCR). For the isolation of RNA, $500 \mathrm{ml}$ of mid-exponential phase $B$. burgdorferi cells $\left(10^{7}\right.$ cells $\left.\mathrm{ml}^{-1}\right)$ were harvested and washed with cold $0.13 \mathrm{mM}$ phosphatebuffered saline $(0.145 \mathrm{M}$ sodium chloride, $0.15 \mathrm{M}$ sodium phosphate, $\mathrm{pH} 7 \cdot 4$ ) twice. Total RNA was isolated with Tri Reagent (Sigma) according to the manufacturer's instructions and treated with DNase (Promega). Further purification of RNA was completed using a Qiagen RNA isolation kit. Primer extension was carried out by using AMV Reverse Transcriptase Primer Extension System (Promega) with modification. Briefly, $15 \mathrm{pmol}$ of reverse primer (5'-GCGACCTCTTTAAGTCCT-3' for the flgK promoter and $5^{\prime}$ TGTAATCAATCTACGAGC- $3^{\prime}$ for the $f$ la $B$ promoter) were labelled with $\left[\gamma_{-}{ }^{32} \mathrm{P}\right] \mathrm{ATP}$ at $37^{\circ} \mathrm{C}$ for $30 \mathrm{~min}$, and purified with a Qiagen Nucleotide Cleaning kit. For primer extension, $1 \mu \mathrm{l}$ (50 fmol) ${ }^{32} \mathrm{P}$-labelled primer was mixed with $50 \mu \mathrm{g}$ RNA and incubated at $58^{\circ} \mathrm{C}$ for $20 \mathrm{~min}$. AMV reverse transcriptase and other reagents were then added and the extension reaction was
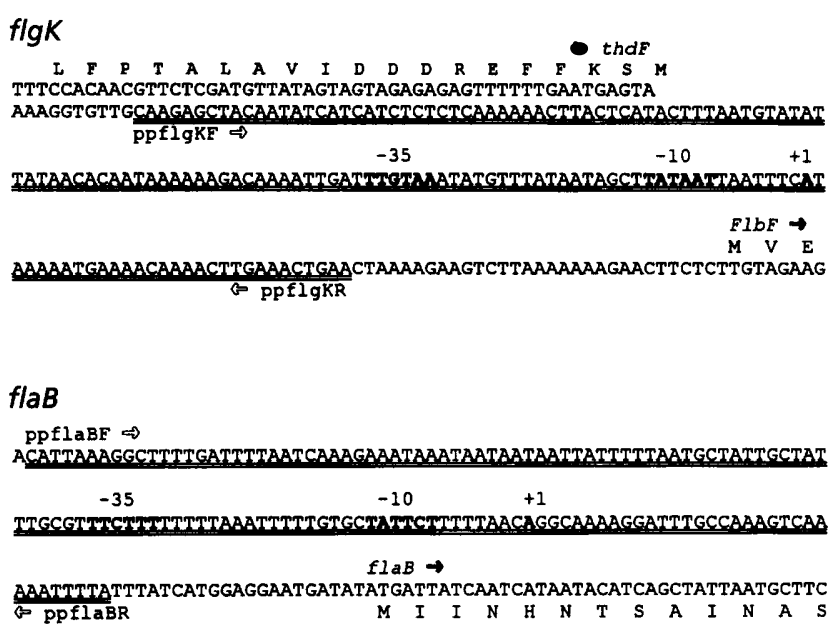

Fig. 1. Promoter elements of flgK and flaB operons which were amplified and cloned into the promoter probe vector. The double-underlined sequences are the amplified regions.

carried out at $41^{\circ} \mathrm{C}$ for $30 \mathrm{~min}$. The products were precipitated with ethanol and resuspended in $4 \mu$ l loading buffer. The primer products were run along with a sequence ladder generated from the same primers.

RT-PCR was carried out by the method described by Limberger et al. (1996). Briefly, 500 ng total RNA was mixed with appropriate reverse primers, 1 unit RNase inhibitor (Promega), 1 unit Superscripts-H reverse transcriptase (Life Technology) and the required reagents according to the manufacturer's protocol. The mixture was incubated for $25 \mathrm{~min}$ at $42^{\circ} \mathrm{C}$ followed by $5 \mathrm{~min}$ at $99^{\circ} \mathrm{C}$ to inactivate reverse transcriptase. The synthesized $\mathrm{cDNA}$ was amplified after adding the appropriate forward primer by a PCR reaction of 35 cycles consisting of $1 \mathrm{~min}$ at $94^{\circ} \mathrm{C}, 1 \mathrm{~min}$ at $52^{\circ} \mathrm{C}$ and $1 \mathrm{~min}$ at $72{ }^{\circ} \mathrm{C}$. The amplified products were analysed in $2 \%$ agarose gels.

Analysis of flgK and flaB promoter elements in E. coli. A plasmid, pKK232-8, containing a promoterless cat gene was used to test for function and strength of the promoter elements from two flagellar operons (Brosius, 1984). The regions containing putative $f l g K$ and $f l a B$ promoter elements were amplified by using primer pairs, ppflgKF/ppflgKR and ppflaBF/ppflaBR, respectively (Fig. 1). Both pairs of primers have a $B a m \mathrm{HI}$ site at the $5^{\prime}$-end and a HindIII site at the 3 '-end. 
The amplified PCR products were cloned into the BamHI/ HindIII sites of pKK232-8, resulting in the plasmids ppflgK ( $f g K$ promoter) and ppflaB (flaB promoter, Table 1). After transformation, the recombinants were selected on ampicillin plates with or without chloramphenicol. An MIC assay was used to determine relative promoter strength. In brief, the $E$. coli HB101 transformants harbouring promoter probe constructs were grown at $37^{\circ} \mathrm{C}$ in $5 \mathrm{ml} 2 \mathrm{YT}$ broth containing $100 \mu \mathrm{g}$ ampicillin $\mathrm{ml}^{-1}$ to an $\mathrm{OD}_{600}$ of $1 \cdot 0$. Diluted cultures were plated onto 2 YT medium containing $2-1000 \mu \mathrm{g}$ chloramphenicol ml $\mathrm{m}^{-1}$ and $100 \mu \mathrm{g}$ ampicillin $\mathrm{ml}^{-1}$, and examined for growth after incubation at $37^{\circ} \mathrm{C}$. Each test was performed in duplicate. The MIC was calculated as the lowest concentration of chloramphenicol at which no growth was discernible. The quantity of CAT protein in the transformed cells was determined in two separate experiments using an ELISA kit from Boehringer Mannheim. Five millilitres of exponential-phase cells were collected by centrifugation, and after lysing the cells, the concentration of CAT protein was determined according to the manufacturer's protocol. Results are expressed as pg CAT protein (mg total cell protein $)^{-1}$.

\section{RESULTS AND DISCUSSION}

\section{Mapping and orientation of flgK operon}

In a clone containing the region around the $185 \mathrm{~kb}$ point of the chromosome, a partial ORF ( $f l g K)$ encoding a protein with similarity to HAP1 was identified. We sequenced the upstream region of the clone and identified an ORF ( $f b F$, see below). We used SRPCW to amplify the remaining portion of the $f g K$ gene and downstream region. After testing several specific and random primers, successful amplification of the desired region was achieved. A $3.0 \mathrm{~kb}$ fragment containing part of $f l g K$ and the downstream region was obtained and cloned into an appropriate vector for sequencing. The fragment was further verified as containing $f l g K$ by PCR using specific primer pairs. Two other genes, $f l g L$ and orf X, were identified downstream of $\mathrm{flgK}$.

The $f g K$ gene cluster is transcribed in an opposite direction to the adjacent non-flagellar $t h d F$ gene (I. Saint Girons \& I. Old, unpublished; Fig. 2). The flgK gene cluster is the fourth flagellar gene cluster identified in $B$. burgdorferi. The others include a single $f l a B$ gene operon localized at $124 \mathrm{~kb}$ (Saint Girons et al., 1994), a large flgB operon at $300-310 \mathrm{~kb}$ (Ge et al., 1996; Saint Girons et al., 1994; unpublished) and a cheA-cheW operon at $725 \mathrm{~kb}$ (G. Treuba, I. Old, I. Saint Girons \& R. C. Johnson, unpublished). These results suggest that, like

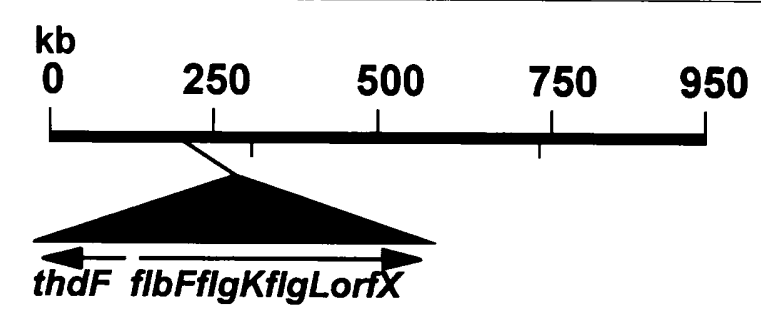

Fig. 2. Gene order and orientation of the flgK operon and adjacent thdF gene on Borrelia burgdorferi 212 chromosome. flagellar genes in other bacteria (Macnab, 1996; Zuberi et al., 1991), B. burgdorferi flagellar genes constitute large gene clusters and are distributed on the chromosome at specific loci. These loci are likely to be part of a large flagellar motility-chemotaxis regulon.

\section{Sequence analysis of the flgK cluster}

The first gene in this region is an ORF of $435 \mathrm{bp}$ encoding a deduced protein of 145 amino acids. In order to simplify the nomenclature of this gene of unknown function, and because it is adjacent to flgK, we designated this gene $f b F$ (flagellar gene of Borrelia). $f l b F$ begins with the start codon TTG (Fig. 1). There are several reasons for assigning TTG rather than ATG as the translational start site. First, initiation at TTG is consistent with primer extension analysis (see below). The ATG at $51 \mathrm{bp}$ upstream of TTG is incorrectly positioned relative to the transcriptional start site to serve as the initiation codon. Second, there is a putative RBS, AAAGA, immediately before the TTG codon; an RBS is not present in front of the ATG sequence. Finally, the start codons of other flagellar genes from $B$. burgdorferi and other bacteria, in particular B. subtilis, are TTG or GTG (Ge et al., 1996; Hardham et al., 1995; Zuberi et al., 1991). The putative gene product of $f l b F$ shows weak homology $(40 \%$ similarity) with a putative flagellar protein, Orf139, from a homologous flagellar operon of B. subtilis (Mirel et al., 1994). Since flagellar genes are clustered by function, $f l b F$ is most likely involved in the final stage of flagellar assembly.

Immediately after $f b F$ is a large 1881 bp ORF encoding a 627 amino acid protein with a molecular mass of $71 \mathrm{kDa}$. The deduced protein product of this gene, designated $f l g K$, shows highest homology with the $\mathrm{N}$ terminal region of $B$. subtilis HAP1 (35\% identity, $76 \%$ similarity; only the N-terminal sequence of $B$. subtilis HAP1 is accessible). It also shows weak homology with HAP1 of Vibrio parahaemolyticus (22\% identity, $53 \%$ similarity) and S. typhimurium (26\% identity, $52 \%$ similarity). B. burgdorferi HAP1 is similar in size to its counterparts found in V. parahaemolyticus (646 amino acids) but larger relative to that of $S$. typhimurium (553 amino acids). The $B$. burgdorferi flg $L$ homologue (1278 bp) is immediately downstream of $f l g K$ (Fig. 2). Its putative gene product, HAP3, a 425 amino acid polypeptide, also demonstrated homology with its counterparts from $V$. parahaemolyticus (17\% identity, $54 \%$ similarity) and $S$. typhimurium (18\% identity, $46 \%$ similarity). In addition, $B$. burgdorferi HAP3 shows weak sequence homology to flagellin proteins (FlaB) from many species of bacteria, including $B$. burgdorfer $i$ and Treponema pallidum (data not shown). Immediately downstream of $f l g L$ a potential ORF was identified and designated as orf $X$. Only one bp separates the flgL stop codon and the orf $X$ start codon. Because only limited sequence data is available (67 bp), we tentatively designate orf $X$ as a potential ORF.

B. burgdorferi flgK and $f l g L$ are likely to have functions similar to their counterparts in other bacteria. We and 


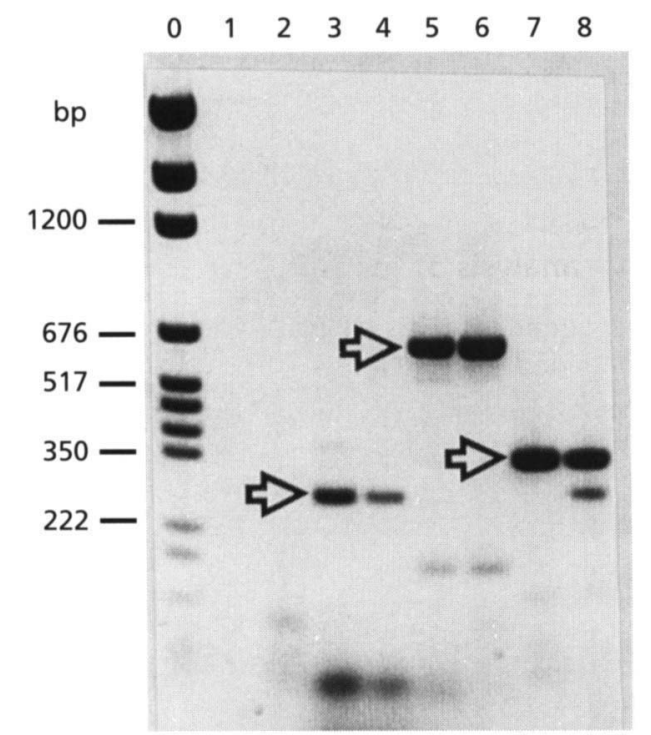

Fig. 3. RT-PCR products after electrophoresis in a $2 \%$ agarose gel and staining with ethidum bromide. The image was obtained with the Eagle Eye system (Stratagene). Lane 0 contains digested pGEM markers; lanes 1, 3, 5 and 7 contain total RNA from the HB19Fla mutant; and lanes 2, 4, 6 and 8 contain total RNA from wild-type $B$. burgdorferi cells. The amplified products were obtained from pairs of primers which span the intergenic regions: flbF-flgK (lanes 3 and 4), flgK-flgL (lanes 5 and 6 ) and flgL-orfX (lanes 7 and 8 ). Lanes 1 and 2 are negative controls using primers generated from thd $F$ and $f l b F$. Arrows point to amplified products of predicted size.

others have found that hook-basal body complexes of B. burgdorferi are very similar in structure to those of E. coli or S. typhimurium but lack the $\mathrm{L}$ and $\mathrm{P}$ rings associated with the Gram-negative outer membrane (Hovind Hougen, 1984; Kreiling, 1995). HAP1 and HAP3 form the junction between the flagellar hook and filament in S. typhimurium (Macnab, 1996). Both proteins are necessary for filament assembly onto the hook. HAP1 and HAP3 serve as an adaptor to connect the inner domains of the flagellar hook to the filament (Aizawa, 1996; Homma \& lino, 1985; Homma et al., 1984; Macnab, 1996).

\section{The figK cluster is organized as an operon}

Examination of the DNA sequence of $f l b F, f l g K, f l g L$ and orf $X$ indicates that these genes are likely to be transcribed as a polycistronic message. To test this, we determined if a single message encoded the proteins using RT-PCR. We chose DNA primers specific to two adjacent genes, and determined whether the message extended through both genes. To ensure the validity of this assay, we used primers from $f l b F$ and $t h d F$ which are obviously transcribed in opposite directions as a negative control (Fig. 1). The results obtained indicated that the assay was valid; the control did not yield products. On the other hand, using the RT-PCR products, the predicted values were obtained between $f l b F$ and $f l g K$, $f l g K$ and $f l g L$, and $f l g K$ and orf $X$ (Fig. 3). These results
B. burgdorferi

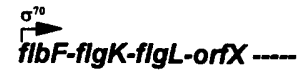
B. subtilis
V. parahaemolyticus
E. coli
C. crescentus

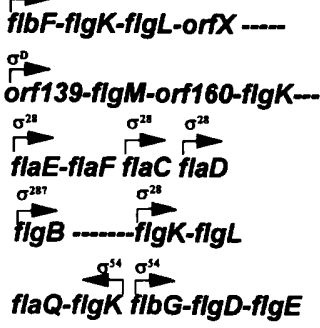

Fig. 4. Comparison of the flgK operon of $B$. burgdorferi with that of other bacteria (Macnab, 1996; McCarter, 1995; Mirel et al., 1994; Ramakrishnan et al., 1994). Transcriptional directions are marked with arrows. The appropriate promoter elements are presented upstream of the first gene for each operon. (a)

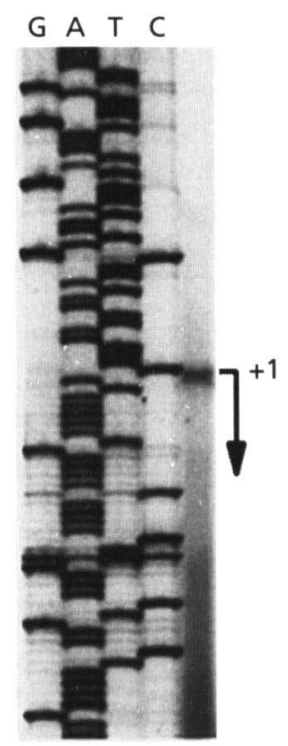

(b)

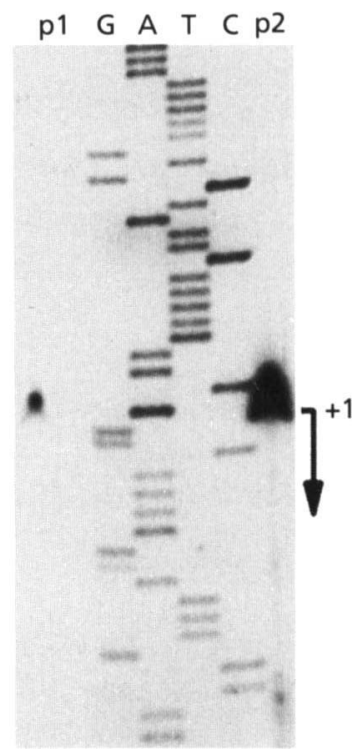

Fig. 5. Primer extension of the $f \lg K(a)$ and $f / g B(b)$ operons in a $6 \%$ polyacrylamide gel. The start site is marked by +1 . The exposure times for $p 1$ and $p 2$ were $10 \mathrm{~h}$ and $48 \mathrm{~h}$, respectively.

suggest that these genes are transcribed as a single polycistronic mRNA.

In comparing the organization of the $\mathrm{fgK}$ operon to those of other bacteria, we found several interesting features (Fig. 4). flgK and $f l g L$ were always adjacent to one another, and $f l g K$ always preceded $f l g L$. In contrast, the flanking regions demonstrated many variations from one species to another. In E. coli and S. typhimurium, $f l g K$ and $f l g L$ constitute the last operon within a flagellar gene cluster (region I), and there are two operons ( $f l g A$ and $f l g B$ ) upstream of $f g K$ (Macnab, 1996); in $V$. parabaemolyticus, flaE (the flgK homologue) with flaF (flgL homologue) comprises the first operon followed by two single flagellin gene operons $(f l a C$ and $f a D$ ) (McCarter, 1995). In C. crescentus, flgK and flaQ (function unknown) form an operon with an orientation opposite to a hook-related operon containing $f l b G, f l g D$ 


\begin{tabular}{|c|c|c|}
\hline & -10 & Reference \\
\hline$\sigma^{28}(f l i A)$ & 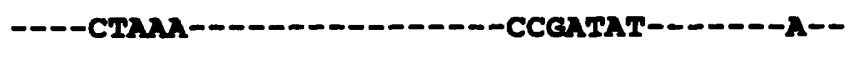 & Macnab (1992) \\
\hline$\sigma^{70}$ & 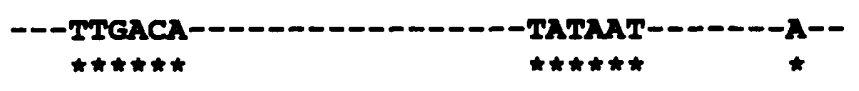 & Harley \& Reynolds (1987) \\
\hline$f l g K(B b)$ & 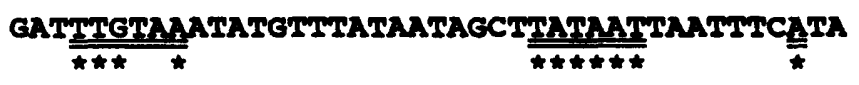 & This study \\
\hline$f l a B(B b)$ & 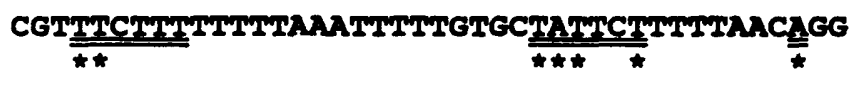 & This study \\
\hline$f l a B(B b)$ & GCGTWTCTITITITITAATIWWTGTECTATTCTIIWTAACAG & Noppa et al. (1995) \\
\hline$f l a A(B b)$ & 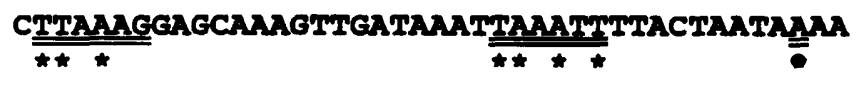 & Ge \& Charon (1997) \\
\hline flaA (Sa) & 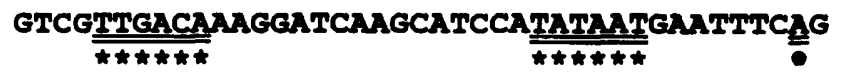 & Parales \& Greenberg (1993) \\
\hline$f l a A(T p)$ & 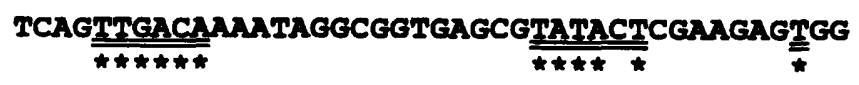 & Issacs \& Radolf (1990) \\
\hline flaA (Sh) & TATTWTGGCAACTYCATATAGTCAGTPAGATTGTCGGATAC & Koopman et al. (1993) \\
\hline
\end{tabular}

Fig. 6. Comparison of the sequences of $B$. burgdorferi $(B b) f l g K, f l a B$ and flaA promoters with those of $\sigma^{28}$ and $\sigma^{70}$ and with other reported spirochaete motility promoter sequences: flaA from Spirochaeta aurantia (Sa), flaA from Treponema pallidum (Tp) and flaA from Serpulina hyodysenteriae (Sh). The nucleotides marked with an asterisk are those identical to the $\sigma^{70}$ consensus sequence.

and flgE (Anderson et al., 1995; Ramakrishnan et al., 1994). In contrast, the structure of the B. subtilis flgK operon resembles that of $B$. burgdorferi. Four B. subtilis genes have been identified with the order orf139, flgM, orf160 and flgK (Mirel et al., 1994). orf139 and orf160 have unknown function, but orf139 has homology with $B$. burgdorferi flbF. Apparently, orf160 and flgM, the latter of which encodes an anti- $\sigma^{28}$ factor (Hughes et al., 1993; Iyoda \& Kutsukake, 1995; Macnab, 1996), are missing from this operon in B. burgdorferi. These results are consistent with the evidence presented below that B. burgdorferi lacks a flagellar-specific $\sigma$ factor.

\section{Determination of flgK and flaB operon promoters}

To investigate the transcriptional regulation of the $f \lg K$ operon in B. burgdorferi, transcriptional initiation was analysed by primer extension. A clear start signal was detected upstream of $f l b F 59$ bp relative to its deduced initiation codon, TTG. Analysis of the upstream sequence indicated a typical $\sigma^{70}$-like promoter at the -10 and -35 region (Fig. $5 \mathrm{a}$ ). Significantly, the -10 region is $100 \%$ identical to the $E$. coli consensus Pribnow box (Harley \& Reynolds, 1987) (Fig. 6), but there is some degree of variation in the -35 region. Because transcription of housekeeping genes is often initiated by $\sigma^{70}$. like promoters (Gralla \& Collado-Vides, 1996), the genes in this $\operatorname{lgK}$ operon could be continuously ex- pressed in B. burgdorferi. Consistent with these results is the finding that the PF proteins of $B$. burgdorferi are present throughout its life cycle as surveyed in bacteria from ticks (T. Schwan, personal communication), animals and those cultured in vitro (Magnarelli et al., 1996). The distinct -35 region could be related to modulation of transcription, as this region binds factors which influence transcriptional expression (Ishihama, 1992). Along these lines, a B. burgdorferi gene encoding a $\sigma^{70}$-like factor has been identified and sequenced (Tsai \& Pan, 1996). Analysis of this gene indicated that the -10 binding region was well conserved when compared to that of other bacteria, whereas the -35 binding region was less conserved (Tsai \& Pan, 1996).

This is the first report to our knowledge of a $\sigma^{70}$-like promoter committed to transcription of a typical 'class 3' flagellar operon in bacteria. As illustrated in Fig. 4, four other bacterial $f l g K$ operons from $E$. coli/ S. typhimurium, B. subtilis, C. crescentus and V. parahaemolyticus have been characterized (Macnab, 1996; McCarter, 1995; Mirel et al., 1992; Ramakrishnan et al., 1994). Transcriptional analyses indicate that expression of the class $3 \mathrm{flgK}$ and $f i D$ operons in S. typhimurium are dependent on the $\sigma^{28}$ factor along with class 2 transcription initiation (Kutsukake \& Ide, 1995). In both $B$. subtilis and V. parahaemolyticus, the $f g K$ operon is initiated from a typical $\sigma^{28}$ consensus promoter 
Table 2. Analysis of promoter strength by MIC and CAT assays

\begin{tabular}{|c|c|c|c|c|}
\hline \multirow[t]{2}{*}{ Host cell } & \multicolumn{4}{|c|}{ MIC $\left(\mu \mathrm{g} \mathrm{ml}^{-1}\right) / \mathrm{CAT}$ concn [pg ( $\mu \mathrm{g}$ total cell protein) $\left.)^{-1}\right]$} \\
\hline & pKK232-8 & pER187* & ppflgK & ppflaB \\
\hline $\begin{array}{l}\text { E. coli HB101 } \\
\text { (wild-type) }\end{array}$ & $2 / \mathrm{ND}$ & $64 / \mathrm{ND}$ & $1000 / \mathrm{ND}$ & $4 / \mathrm{ND}$ \\
\hline $\begin{array}{l}\text { S. typhimurium KK1203 } \\
\text { (wild-type) } \dagger\end{array}$ & $8 / 0$ & $86 / 10$ & $1000 / 3030$ & $4 / 0$ \\
\hline $\begin{array}{l}\text { S. typhimurium KK1401 } \\
\text { (fliA mutant) } \dagger\end{array}$ & $4 / 0$ & $86 / 10$ & $1000 / 3060$ & $2 / 0$ \\
\hline
\end{tabular}

ND, Not determined.

*Provided by K. Kutsukake, Hiroshima University, Japan.

†Provided by E. Rosey, Pfizer, Groton, CT, USA.

(McCarter, 1995; Mirel et al., 1994). A similar flagellarspecific sigma factor $\left(\sigma^{54}\right)$ is involved in the transcription of the flgK operon in C. crescentus (Ramakrishnan et al., 1994). Clearly, transcription of all previously characterized $\mathrm{flgK}$ operons is initiated by class 2 and class 3 promoters and by a family of flagellar-specific sigma factors $\left(\sigma^{28}\right.$ or $\left.\sigma^{54}\right)$, which is very distinct from what is found with B. burgdorferi.

Recently, primer extension analysis yielded different conclusions concerning the promoter sequences involved in transcription of the flaB gene in B. burgdorferi. Gassmann et al. (1991) suggest that a $\sigma^{70}$-like promoter is involved in $f l a B$ transcription. On the other hand, Noppa et al. (1995) suggested that a B. subtilis bacteriophage $\sigma^{\mathrm{gp} 33-34}$-like promoter is involved in transcription of this gene. The results which show the $B$. burgdorferi flaB promoter being transcribed from a

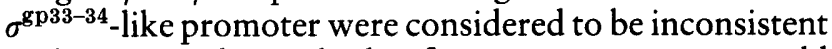
with our results with the $\lg K$ operon, as we would expect this class 3 operon also to be regulated by a $\sigma^{70}$ like promoter. Along these lines, we recently identified $\sigma^{70}$-like promoters involved in the transcription of several other $\mathrm{fla} / \mathrm{che}$ operons of $\mathrm{B}$. burgdorferi (unpublished). To examine whether $f l a B$ is transcribed from a $\sigma^{g \mathbf{p} 33-34}$-like promoter, we re-examined the promoter element of B. burgdorferi flaB. To obtain the upstream region of $f l a B$ of strain 212, we used SRPCW and a primer based on the published sequenced of $f a B$ (Wallich et al., 1990). The promoter region we obtained for strain 212 is essentially identical to that of strain B31 except for a single base pair difference (Noppa et al., 1995). Our primer extension results indicate that the transcriptional start site is $1 \mathrm{bp}$ downstream of the reported start site as shown in Fig. 5(b). The sequence around the -10 region revealed a putative $\sigma^{70}$-like promoter (TATTCT) 7 bp upstream of the start site, although this region is not as well conserved as that of the flgK operon. Gassmann et al. (1991) also propose these same nucleotides as the -10 region for $\mathrm{flaB}$. As with the $f l g K$ operon, the -35 region of the $f l a B$ operon is different from that of a typical $\sigma^{70}$-like promoter. These results suggest that a $\sigma^{70}$-like rather than a $\sigma^{\text {gp33-34 }}$ like promoter could be involved in the transcription of flaB operon.

Little is known about transcriptional regulation of the flagellar genes of spirochaetes. A $\sigma^{28}$-like promoter sequence was localized by primer extension at a region upstream of a large flagellar cluster in $T$. pallidum and Treponema phagedenis (Limberger et al., 1996). In T. pallidum, T. phagedenis, Serpulina hyodysenteriae, and Spirochaeta aurantia, the flagellar flaB filament genes are transcribed from a $\sigma^{28}$-like promoter (Champion $e t$ al., 1990; Charon et al., 1992; Koopman et al., 1993; Limberger et al., 1992; Pallesen \& Hindersson, 1989). In addition, the $f l a A$ gene, which encodes the flagellar sheath in Se. hyodysenteriae, T. pallidum and $S p$. aurantia has a very well conserved $\sigma^{70}$-like promoter (Fig. 6) (Isaacs \& Radolf, 1990; Koopman et al., 1992; Parales \& Greenberg, 1993).

\section{Functional analyses of $\mathrm{flaB}$ and flgK promoter}

We examined whether promoter elements from $f l g K$ and $f l a B$ function to initiate transcription in E. coli and S. typhimurium. We also examined whether expression occurred in a fliA motility mutant of $S$. typhimurium defective in a $\sigma^{28}$ factor. We used the promoter selection vector pKK232-8 in this analysis (Brosius, 1984). This plasmid vector contains a promoterless cat gene with stop codons in three different frames between the polylinker site and cat gene to prevent translational read through from vector genes. It also has a strong transcriptional terminator upstream of the polylinker site. Several different constructs were cloned into pKK232-8 and transformed into E. coli or S. typhimurium. The flgK promoter elements enabled both the $E$. coli and $S$. typhimurium parents and the fliA mutant to be resistant to an extremely high concentration of chloramphenicol with MICs of $1 \mathrm{mg} \mathrm{ml}^{-1}$, while the cells harbouring the $f l a B$ promoter showed almost no resistance to chloramphenicol (Table 2). The activity of the flgK promoter was even higher than the positive control (pER187). The plasmid pER187 contains a cat gene of Staphylococcus aureus with its own promoter. ELISA assays agreed with the MIC results, as high concentrations of CAT protein 
were detected in the ppflgK-transformed cells, a lower level in the control, but none in cells transformed by ppflaB (Table 2). These results suggest that the flgK promoter of B. burgdorferi is functional in E. coli and $S$. typhimurium. In addition, because CAT expression was high in the fliA mutant, a $\sigma^{70}$-like rather than a $\sigma^{28}$ factor is most likely involved in the transcription of these genes. It is not clear why the flaB promoter is not functional in E. coli or S. typhimurium; perhaps there are other transcriptional factors involved in the expression of $B$. burgdorferi flaB. In addition, we cannot exclude the role of the putative $\sigma^{\mathrm{gp} 33-34}$-like promoter in its transcription.

\section{Analysis of a flagella-less mutant}

Several years ago Sadziene et al. (1991) isolated a spontaneously occurring nonmotile mutant from $B$. burgdorferi strain $\mathrm{HB} 19$ (HB19Fla $\left.{ }^{-}\right)$. Although this mutant lacked detectable FlaB protein, the $f l a B$ gene was transcribed at a level identical to the wild-type. Although the location of the gene which is altered in this mutant is unknown, it is likely that it suffered a mutation in a gene involved in the late stage of flagellar synthesis. Specifcally, electron microscopy revealed that this mutant had intact hook-basal body structures (Sadziene et al., 1991). Because mutations in either flgK or flgL result in the flagella-less mutants with intact hook-basal bodies in other bacteria (Jones \& Macnab, 1990), we hypothesized that the flgK operon could be altered in $\mathrm{HB} 19 \mathrm{Fla}^{-}$. To test this, we amplified the region between $A b F$ and orfX in both wild-type HB19 and HB19Fla ${ }^{-}$. Neither an insertion nor a deletion in this region was detected in $\mathrm{HB}$ 19Fla ${ }^{-}$(data not shown). In addition RT-PCR analysis indicated that $\mathrm{HB} 19 \mathrm{Fla}^{-}$produced detectable levels of mRNA from this region (Fig. 3). Although we are unable to exclude the possibilities that point mutations, or small insertions or deletions exist in this region, our results indicate that there is no obvious transcriptional defect, insertion or deletion present in the $\mathrm{flgK}$ operon in $\mathrm{HB} 19 \mathrm{Fla}^{-}$.

The study of the transcriptional regulation in spirochaetes has just begun, and many questions need to be answered. For example, we do not understand the mechanism underlying the transcriptional cascade of flagellar synthesis of $B$. burgdorferi. Our results suggest that a $\sigma^{70}$-like rather than a $\sigma^{28}$-like factor is involved in flagellar gene transcription. The conclusion drawn from this and our previous analyses must be that the transcriptional pathway of the $B$. burgdorferi flagellar operons is distinct from those of other bacteria, including other spirochaete species.

\section{ACKNOWLEDGEMENTS}

We thank L. Wang for technical assistance in RNA manipulation, A. Barbour for $\mathrm{HB} 19 \mathrm{Fla}^{-}$, and E. Rosey and K. Kutsukake for E. coli and S. typhimurium strains and plasmids. We thank D. Yelton and $\mathrm{H}$. Thompson for critical reading of the manuscript, and $T$. Schwan for communicating unpublished information. This research was supported in part by Public Health Service Grant AI29743.

\section{REFERENCES}

Aizawa, S. I. (1996). Flagellar assembly in Salmonella typhimurium. Mol Microbiol 19, 1-5.

Anderson, D. K., Ohta, N., Wu, J. \& Newton, A. (1995). Regulation of the Caulobacter crescentus rpoN gene and function of the purified $\sigma^{54}$ in flagellar gene transcription. Mol Gen Genet 246, 697-706.

Armitage, J. P. (1992). Behavioral responses in bacteria. Annu Rev Physiol 54, 683-714.

Ausubel, F. M., Brent, R., Kingston, R. E., Moore, D. D., Seidman, G. G., Smith, J. A. \& Struhl, K. (1995). Current Protocols in Molecular Biology. New York: Wiley.

Barbour, A. G. (1984). Isolation and cultivation of Lyme disease spirochetes. Yale J Biol Med 57, 521-525.

Brosius, J. (1984). Plasmid vectors for the selection of promoters. Gene 27, 151-160.

Canale-Parola, E. (1978). Motility and chemotaxis of spirochetes. Annu Rev Microbiol 32, 69-99.

Champion, C. I., Miller, J. N., Lovett, M. A. \& Blanco, D. R. (1990). Cloning, sequencing, and expression of two class $B$ endoflagellar genes of Treponema pallidum subsp. pallidum encoding the 34.5and 31·0-kilodalton proteins. Infect Immun 58, 1697-1704.

Charon, N. W., Greenberg, E. P., Koopman, M. B. H. \& Limberger, R. J. (1992). Spirochete chemotaxis, motility, and the structure of the spirochetal periplasmic flagella. Res Microbiol 143, 597-603.

Fredrick, K. L. \& Helmann, J. D. (1994). Dual chemotaxis signaling pathways in Bacillus subtilis: a $\sigma^{\mathbf{D}}$-dependent gene encodes a novel protein with both $\mathrm{Ch}$ W and CheY homologous domains. J Bacteriol 176, 2727-2735.

Fredrick, K., Caramori, T., Chen, Y.-F., Galizzi, A. \& Helmann, J. D. (1995). Promoter architecture in the flagellar regulon of Bacillus subtilis: high-level expression of flagellin by the $\sigma^{\mathrm{D}}$ RNA polymerase requires an upstream promoter element. Proc Natl Acad Sci USA 92, 2582-2586.

Gassmann, G. S., Jacobs, E., Deutzmann, R. \& Gobel, U. B. (1991). Analysis of the Borrelia burgdorferi $\mathrm{GeHo} f l a$ gene and antigenic characterization of its gene product. J Bacteriol 173, 1452-1459.

Ge, Y. G., Old, I., Saint Girons, I., Yelton, D. B. \& Charon, N. W. (1996). FliH and FliI of Borrelia burgdorferi are similar to flagellar and virulence factor export proteins of other bacteria. Gene 168, $73-75$.

Ge, Y. \& Charon, N. W. (1997). An unexpected flaA homolog is present and expressed in Borrelia burgdorferi. J. Bacteriol 179, 552-556.

Goldstein, S. F., Charon, N. W. \& Kreiling, J. A. (1994). Borrelia burgdorferi swims with a planar waveform similar to that of eukaryotic flagella. Proc Natl Acad Sci USA 91, 3433-3437.

Goldstein, S. F., Buttle, K. F. \& Charon, N. W. (1996). Structural analysis of Leptospiraceae and Borrelia burgdorferi using high voltage electron microscopy. J Bacteriol 178, 6539-6545.

Gralla, J. D. \& Collado-Vides, J. (1996). Organization and function of transcription regulatory elements. In Escherichia coli and Salmonella: Cellular and Molecular Biology, pp. 1232-1245. Edited by F. C. Neidhardt and others. Washington, DC: American Society for Microbiology.

Hardham, J. M., Frye, J. G. \& Stamm, L. V. (1995). Identification and sequences of the Treponema pallidum fliM', fliY, fliQ, fliR, and $f h B^{\prime}$. Gene 166, 57-64.

Harley, C. B. \& Reynolds, R. P. (1987). Analysis of E. coli promoter sequences. Nucleic Acids Res 15, 2343-2361. 
Helmann, J. D. (1991). Alternative sigma factors and the regulation of flagellar gene expression. Mol Microbiol 5, 2875-2882.

Homma, M. \& lino, T. (1985). Locations of hook-associated proteins in flagellar structures of Salmonella typhimurium. J Bacteriol 162, 183-189.

Homma, M., Kutsukake, K., lino, T. \& Yamaguchi, S. (1984). Hook-associated proteins essential for flagellar filament formation in Salmonella typhimurium. J Bacteriol 157, 100-108.

Hovind Hougen, K. (1984). Ultrastructure of spirochetes isolated from Ixodes ricinus and Ixodes dammini. Yale J Biol Med 57, 543-548.

Hughes, K. T., Gillen, K. L., Semon, M. J. \& Karlinsey, J. E. (1993). Sensing structural intermediates in bacterial flagellar assembly by export of a negative regulator. Science 262, 1277-1280.

Isaacs, R. D. \& Radolf, J. D. (1990). Expression in Escherichia coli of the 37-kilodalton endoflagellar sheath protein of Treponema pallidum by use of the polymerase chain reaction and a T7 expression system. Infect Immun 58, 2025-2034.

Ishihama, I. (1992). Role of RNA polymerase $\alpha$ subunit in transcriptional activation. Mol Microbiol 6, 3283-3288.

lyoda, S. \& Kutsukake, K. (1995). Molecular dissection of the flagellum specific anti-sigma factor, FlgM, of Salmonella typhimurium. Mol Gen Genet 249, 417-424.

Johnson, R. C., Schmid, G. P., Hyde, F. W., Steigerwalt, A. G. \& Brenner, D. J. (1984). Borrelia burgdorferi sp. nov.: etiological agent of Lyme disease. Int J Syst Bacteriol 34, 496-497.

Jones, C. J. \& Macnab, R. M. (1990). Flagellar assembly in Salmonella typhimurium: analysis with temperature-sensitive mutants. J Bacteriol 172, 1327-1339.

Kimsey, R. B. \& Spielman, A. (1990). Motility of Lyme disease spirochetes in fluids as viscous as the extracellular matrix. J Infect Dis 162, 1205-1208.

Koopman, M. B. H., de Lee, O. S., van der Zieijst, B. A. M. \& Kuster, J. G. (1992). Cloning and DNA sequence analysis of a Serpulina (Treponema) byodysenteriae gene encoding a periplasmic flagellar sheath protein. Infect Immun 60, 2920-2925.

Koopman, M. B. H., Baats, E., de Leeuw, O. S., van der Zeijst, B. A. M. \& Kusters, J. G. (1993). Molecular analysis of a flagellar core protein gene of Serpulina (Treponema) byodysenteriae. J Gen Microbiol 139, 1701-1706.

Kreiling, J. A. (1995). Characterization of the periplasmic flagella of Borrelia burgdorferi. PhD dissertation, West Virginia University.

Kutsukake, K. \& Ide, N. (1995). Transcriptional analysis of the flgK and fliD operons of Salmonella typhimurium which encode flagellar hook-associated proteins. Mol Gen Genet 247, 275-281.

Limberger, R. J., Slivienski, L. L., Yelton, D. B. \& Charon, N. W. (1992). Molecular genetic analysis of a class $B$ periplasmic flagellum gene of Treponema phagedenis. J Bacteriol 174, 6404-6410.

Limberger, R. J., Slivienski, L. L., El-Afandi, M. C. T. \& Dantuono, L. A. (1996). Organization, transcription, and expression of the 5 ' region of the fla operon of Treponema phagedenis and Treponema pallidum. J Bacteriol 178, 4628-4634.

McCarter, L. L. (1995). Genetic and molecular characterization of the polar flagellum of Vibrio parahaemolyticus. J Bacteriol 177, 1595-1609.

Macnab, R. M. (1996). Flagella and motility. In Escherichia coli and Salmonella: Cellular and Molecular Biology, pp. 1232-1245.
Edited by F. C. Neidhardt and others. Washington, DC: American Society for Microbiology.

Magnarelli, L. A., Fikrig, E., Padula, S. J., Anderson, J. F. \& Flavell, R. A. (1996). Use of recombinant antigens of Borrelia burgdorferi in serologic tests for diagnosis of Lyme borreliosis. J Clin Microbiol 34, 237-240.

Marquez-Magana, L. M. \& Chamberlin, M. J. (1994). Characterization of the sigD transcription unit of Bacillus subtilis. $J$ Bacteriol 176, 2427-2434.

Mirel, D. B., Lustre, V. M. \& Chamberlin, M. V. (1992). An operon of Bacillus subtilis motility genes transcribed by the $\sigma^{D}$ form of RNA-polymerase. J Bacteriol 174, 4197-4204.

Mirel, D. B., Lauer, P. \& Chamberlin, M. J. (1994). Identification of flagellar synthesis regulatory and structural genes in $\sigma^{\mathrm{D}}$-dependent operon of Bacillus subtilis. J Bacteriol 176, 4492-4500.

Mohr, C. D., Jenal, U. \& Shapiro, L. (1996). Flagellar assembly in Caulobacter crescentus: a basal body P-ring null mutation affects stability of the L-ring protein. J Bacteriol 178, 675-682.

Noppa, L., Burman, N., Sadziene, A., Barbour, A. G. \& Bergström, S. (1995). Expression of the flagellin gene in Borrelia is controlled by an alternative $\sigma$ factor. Microbiology 141, 85-93.

Pallesen, L. \& Hindersson, P. (1989). Cloning and sequencing of a Treponema pallidum gene encoding a 31.3 kilodalton endoflagellar subunit (FlaB2). Infect Immun 57, 2166-2172.

Parales, J. \& Greenberg, E. P. (1993). Analysis of the Spirochaeta aurantia flaA gene and transcript. FEMS Microbiol Lett 106, 245-251.

Parker, J. D., Rabinovitch, P. S. \& Burmer, G. C. (1991). Targeted gene walking polymerase chain reaction. Nucleic Acids Res 19, 3055-3060.

Quon, K. C., Marczynski, T. \& Shapiro, L. (1996). Cell cycle control by an essential bacterial two-component signal transduction protein. Cell 84, 83-93.

Ramakrishnan, G., Zhao, J.-L. \& Newton, A. (1994). Multiple structural proteins are required for both transcriptional activation and negative autoregulation of Caulobacter crescentus flagellar genes. J Bacteriol 176, 7587-7600.

Sadziene, A., Thomas, D. D., Bundoc, V. G., Holt, S. C. \& Barbour, A. G. (1991). A flagella-less mutant of Borrelia burgdorferi. Structural, molecular, and in vitro characterization. J Clin Invest 88, 82-92.

Saint Girons, I., Old, I. G. \& Davidson, B. E. (1994). Molecular biology of the Borrelia, bacteria with linear replicons. Microbiology 140, 1803-1816.

Sambrook, J., Fritsch, E. F. \& Maniatis, T. (1989). Molecular Cloning: a Laboratory Manual, 2nd edn. Cold Spring Harbor, NY: Cold Spring Laboratory.

Sanger, F., Nicklen, S. \& Coulson, A. R. (1977). DNA sequencing with chain-terminating inhibitors. Proc Natl Acad Sci USA 74, 5463-5467.

Tsai, C. P. \& Pan, M. J. (1996). Sequence of a gene encoding a putative primary sigma factor from Borrelia burgdorferi strain B31. Gene 168, 123-124.

Wallich, R., Moter, S. E., Sirion, M. M., Ebnet, K., Heiberger, A. \& Kramer, M. D. (1990). The Borrelia burgdorferi flagellum-associated 41-kilodalton antigen (flagellin): molecular cloning, expression, and amplification of the gene. Infect Immun 58, 1711-1719.

Wu, J., Benson, A. K. \& Newton, A. (1995). Global regulation of a $\sigma^{54}$-dependent flagellar gene family in Caulobacter crescentus by the transcriptional activator FlbD. J Bacteriol 177, 3241-3250. 
Zhuang, W. Y. \& Shapiro, L. (1995). Caulobacter FliQ and FliR membrane proteins, required for flagellar biogenesis and cell division, belong to a family of virulence factor export proteins. J Bacteriol 177, 343-356.

Zuberi, A. R., Ying, C., Bischoff, D. S. \& Ordal, G. W. (1991).

Gene-protein relationships in the flagellar hook-basal body complex of Bacillus subtilis: sequences of the $f \lg B, f l g C, f l g G$, fliE, fliF genes. Gene 101, 23-31.

Received 4 September 1996; revised 1 December 1996; accepted 7 January 1997. 